\title{
Modulation of the Random Migration of Human Platelets
}

\author{
Frank H. Valone, K. Frank Austen, and Edward J. Goetzl \\ From the Departments of Medicine, Harvard Medical School and the Robert \\ B. Brigham Hospital, Boston, Massachusetts 02120
}

A в S T R A C T Random migration of human platelets has been recognized as a parameter of platelet function which can be assessed in a reproducible manner by modification of the Boyden micropore filter technique for evaluating this function in other cells (Boyden, $\mathrm{S}$. 1962. J. Exp. Med. 115: 453-466). Because platelets are extremely susceptible to aggregation, the conditions for collecting and isolating platelets and the migration buffer $\left(\mathrm{Ca}^{++}\right.$and $\mathrm{Mg}^{++}$-free phosphate buffered saline, $\mathrm{pH}$ 6.8 , with glucose and gelatin) were selected to minimize such a possibility. The random movement of platelets into the micropore filter was maximal at $30-37^{\circ} \mathrm{C}$ and was contingent upon the metabolic integrity of the cell; thus, it can be attributed to active spontaneous migration. While the initiating and enhancing effects of epinephrine on the platelet aggregation-release reaction are mediated by an $\alpha$-adrenergic receptor, the inhibition of random migration involved a $\beta$-receptor. Equimolar propranolol but not phentolamine prevented epinephrine inhibition of random migration, and isoproterenol had activity comparable to epinephrine while phenylephrine was inactive. The capacity of the cholinomimetic agent, carbachol, to increase platelet migration is reminiscent of the recent findings in several cell systems in which $\boldsymbol{\beta}$-adrenergic and cholinergic stimuli have opposite effects. The prostaglandins $E_{1}$ and $E_{2}$ augmented spontaneous migration in contrast to their well established inhibitory action on platelet aggregation at the concentrations employed. The suppression by indomethacin of prostaglandin enhancement and of spontaneous migration implies a requirement for the prostaglandin biosynthetic pathway during the migration process. Thus, the spontaneous migration of human platelets, an additional parameter of platelet function for in vitro investigations, disclosed not only a $\beta$-adrenergic receptor for epinephrine, but also a capacity for

Mr. Valone is a predoctoral fellow of the Harvard Medical School. Dr. Goetzl is an Investigator of the Howard Hughes Medical Institute.

Received for publication 10 May 1974 and in revised form 22 July 1974. cholinergic augmentation and an apparent requirement for prostaglandin biosynthesis.

\section{INTRODUCTION}

The methods for in vitro assessment of human platelet function have included platelet adherence to synthetic surfaces, aggregation as measured by changes in the optical density of platelet suspensions, and release of specific platelet constituents induced by aggregating agents $(1,2)$ but have not included directed or random migration. The coincidental observation that platelets as well as polymorphonuclear and mononuclear leukocytes moved through a micropore filter during studies of random migration of mixed leukocyte populations prompted a specific investigation of platelet migration. The Boyden chamber method (3) for studying spontaneous and directed migration of various classes of leukocytes was adapted for such platelet studies by appropriate selection of pore size, buffer, and other conditions. This in turn permitted analysis of the effects of adrenergic and cholinergic stimuli and prostaglandins on spontaneous migration of human platelets.

\section{METHODS}

Polystyrene disposable chemotactic chambers (Adaps Inc. Dedham, Mass.) and micropore filters (Millipore Corp., Bedford, Mass.) were assembled as previously described (4). L-epinephrine (Sigma Chemical Co., St. Louis, Mo.), phentolamine (Regitine, Ciba Pharmaceutical Company, Summit, N. J.), propranolol (Inderal, Ayerst Laboratories, New York), gelatin (Difco Laboratories, Detroit, Mich.), and prostaglandins $\mathrm{PGE}_{1}, \mathrm{PGE}_{2}$, and $\mathrm{PGF}_{2 \alpha}$ (The Upjohn Co., Kalamazoo, Mich.) were obtained as noted. Siliconized (Dricote, Fisher Scientific Co., Fair Lawn, N. J.) glassware and needles or plastic materials were used for all platelet suspensions.

Platelet isolation. Fresh human blood was collected from normal volunteers who had taken no drugs known to affect platelet function for at least 5 days before venipuncture. $5-\mathrm{ml}$ portions of blood were mixed with $1 \mathrm{ml}$ of sodium citrate anticoagulant (citric acid $0.076 \mathrm{M}$, sodium citrate $0.15 \mathrm{M}, \mathrm{pH}$ 5.2) in 14-ml plastic tubes and were immediately centrifuged at $200 \mathrm{~g}$ for $15 \mathrm{~min}$ at room temperature. The platelet-rich plasma was removed from the buffy coat 
and red cell infranate and was centrifuged at $900 \mathrm{~g}$ for 20 min. The platelet-poor supernate was discarded, and the platelet pellet was resuspended by repeated gentle aspiration with a pipette in the standard buffered medium $(\mathrm{pH}$ 6.8, $0.005 \mathrm{M} \mathrm{KH}_{2} \mathrm{PO}_{4}, 0.005 \mathrm{M} \mathrm{Na}_{2} \mathrm{HPO}_{4}, 0.1 \mathrm{M} \mathrm{NaCl}, 0.2$ $\mathrm{g} / 100 \mathrm{ml}$ glucose, and $0.5 \mathrm{~g} / 100 \mathrm{ml}$ gelatin). Platelet counts were performed by phase-contrast microscopy.

Platelet migration. $0.5 \mathrm{ml}$ of platelet suspension containing 4-6 $610^{7}$ platelets and less than $0.1 \%$ leukocytes was added to the cell compartment of a modified Boyden chamber which was separated from the medium compartment below by an 8- $\mu \mathrm{m}$ micropore filter. After a 3-h incubation at $37^{\circ} \mathrm{C}$, the filters were washed twice in $0.15 \mathrm{M}$ $\mathrm{NaCl}$, fixed in $10 \%$ (vol/vol) formalin (5) containing 0.15 M sodium acetate ( $\mathrm{pH}$ 7.2) for 1 h, stained with Harris' hematoxylin (5) and mounted on glass slides. All experiments were performed in duplicate or triplicate. Migration into each filter was quantitated by counting the number of platelets in 10 high-power fields $(\mathrm{HPF})^{1}$ at a fixed level for each experiment of $40-70 \mu \mathrm{m}$ from the source of the platelets at the top of the filter. The microscope slides containing the mounted micropore filters were coded and counted in blind fashion by two investigators. The variation in interpretation was less than $20 \%$ of the mean of the separate readings. Modifications of the medium composition or agents tested for their effect on platelet migration were present on both the platelet and medium sides of the filter with no concentration gradient. Statistical analysis of data was performed with a standard paired $t$ test.

\section{RESULTS}

Determination of the optimal conditions for migration

The influence of buffer composition, filter pore size, and conditions of incubation on the rate of migration of platelets was assessed by counting triplicate filters at hourly intervals up to $5 \mathrm{~h}$ for each set of conditions. The time-course of migration for platelets suspended in the standard buffered medium and incubated at $37^{\circ} \mathrm{C}$ always revealed a continuous increase of platelet counts as the duration of incubation increased. After $3 \mathrm{~h}$ of incubation, platelet counts per HPF $50 \mu \mathrm{m}$ from the platelet layer at the top of the micropore filter in a typical experiment were $3-5$ for $3 \mu \mathrm{m}, 9-13$ for $5 \mu \mathrm{m}$, and 19-25 for $8 \mu \mathrm{m}$ pore size. In all subsequent experiments platelets were incubated for $3 \mathrm{~h}$ on $8-\mu \mathrm{m}$ millipore filters and counted at a fixed depth from 40 to $70 \mu \mathrm{m}$ for each experiment.

Platelet migration was maximal at temperatures between 30 and $37^{\circ} \mathrm{C}$ and diminished at either lower or higher temperatures (Fig. 1). $37^{\circ} \mathrm{C}$ was used as the standard temperature for examining all other variables.

The concentration of gelatin in the standard buffered medium was varied between 0 and $3.0 \mathrm{~g} / 100 \mathrm{ml}$. Maximal migration (Fig. 2) occurred between gelatin concentrations of 0.5 and $1.0 \mathrm{~g} / 100 \mathrm{ml}$. All subsequent studies utilized $0.5 \mathrm{~g} / 100 \mathrm{ml}$ gelatin.

${ }^{1}$ Abbreviations used in this paper: HPF, high-power fields; $I_{50}$, dose required for $50 \%$ inhibition of migration.

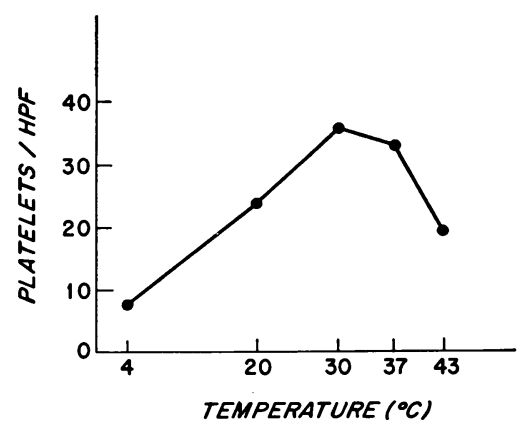

FIGURE 1 Temperature dependence of the random migration of purified human platelets. Each point represents the mean number of platelets per high-power field (HPF) in $8-\mu \mathrm{m}$ pore filters at $50 \mu \mathrm{m}$ from the platelet source for triplicate chambers incubated at specified temperatures for $3 \mathrm{~h}$.

$p H$. In order to provide a broader buffering range Tris (hydroxymethyl)aminomethane $(0.005 \mathrm{M})$ and acetic acid $(0.005 \mathrm{M})$ were added to standard medium without $\mathrm{NaCl}$. The $\mathrm{pH}$ was adjusted to levels between 4.0 and 11.0 with $0.1 \mathrm{M} \mathrm{NaOH}$ or $0.1 \mathrm{M} \mathrm{HCl}$, followed by adjustment of the conductivity with $3.0 \mathrm{M} \mathrm{NaCl}$ to that of the standard buffer $\left(12.6 \mathrm{mS}\right.$ at $\left.22^{\circ} \mathrm{C}\right) . \mathrm{pH}$ and conductivity were recorded after the platelets were suspended in the buffers. A peak of maximal migration was observed between $\mathrm{pH} 5.0$ and 6.5 with a plateau being noted between 6.5 and 8.5 ; migration was not detected at $\mathrm{pH}$ less than 4.5 or greater than 10.0 (Fig. 3).

Calcium, magnesium, and potassium. Because the platelet suspensions in the standard buffered medium contain no added $\mathrm{Mg}^{++}$or $\mathrm{Ca}^{++}$, the concentration re-

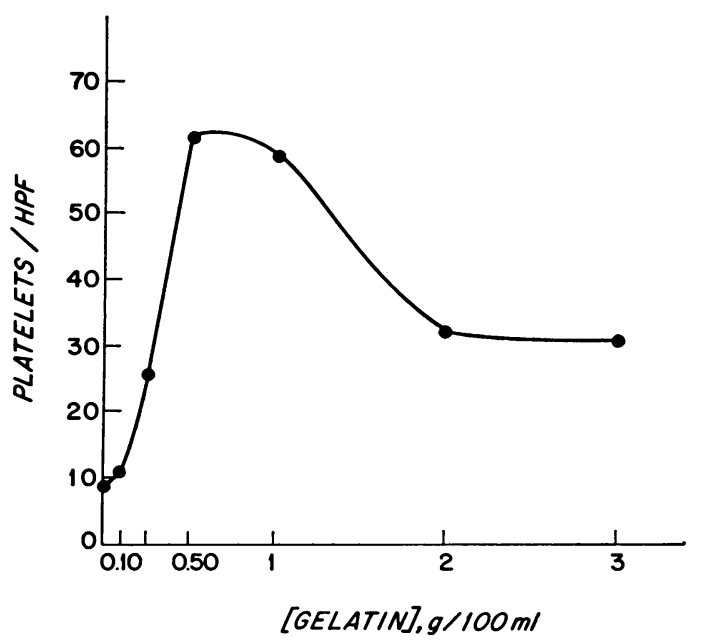

FIGURE 2 Influence of gelatin concentration on the random migration of human platelets. Each point represents the mean number of platelets per HPF at $40 \mu \mathrm{m}$ from the platelet source for triplicate chambers containing buffer constituted to the specified gelatin concentration. 


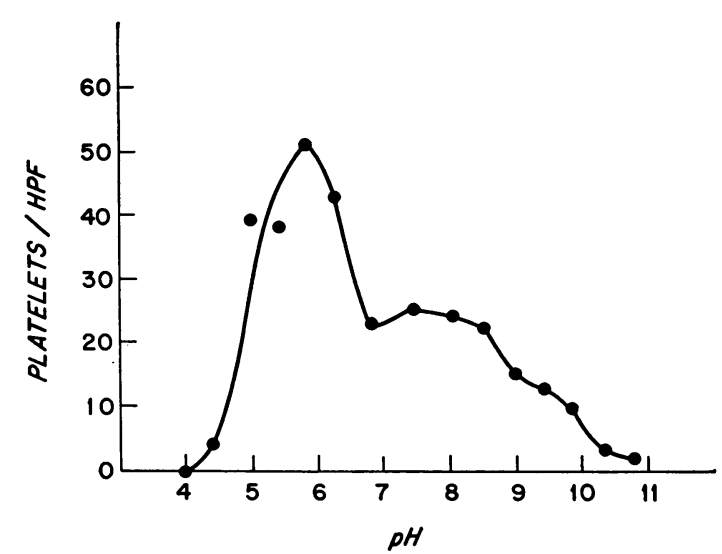

FIGURE 3 Influence of $\mathrm{pH}$ on the random migration of human platelets. The $\mathrm{pH}$ of the standard buffer containing added $0.005 \mathrm{M}$ Tris and $0.005 \mathrm{M}$ acetic acid and no $\mathrm{NaCl}$ was adjusted to the specified values, and the conductivity was then adjusted with $3.0 \mathrm{M} \mathrm{NaCl}$ to that of the standard buffer. Each point represents the mean number of platelets at $60 \mu \mathrm{m}$ from the platelet source in duplicate chambers.

corded (Fig. 4) is that added to the buffer, namely $10^{-2}$ $10^{-6} \mathrm{M}$. Both divalent cations inhibited migration in a dose-related manner at concentrations greater than $10^{-4}$ M. Platelet aggregates were observed on the top of the filters at $10^{-2} \mathrm{M}$. No concentration of these cations increased migration above that seen in the standard $\mathrm{Mg}^{++}$ and $\mathrm{Ca}^{++}$-free medium. Washing platelets three times also did not decrease random migration.

Varying amounts of $\mathrm{KCl}$ were substituted for $\mathrm{NaCl}$ in standard medium made with $\mathrm{NaH}_{2} \mathrm{PO}$ ( $0.005 \mathrm{M}$ )

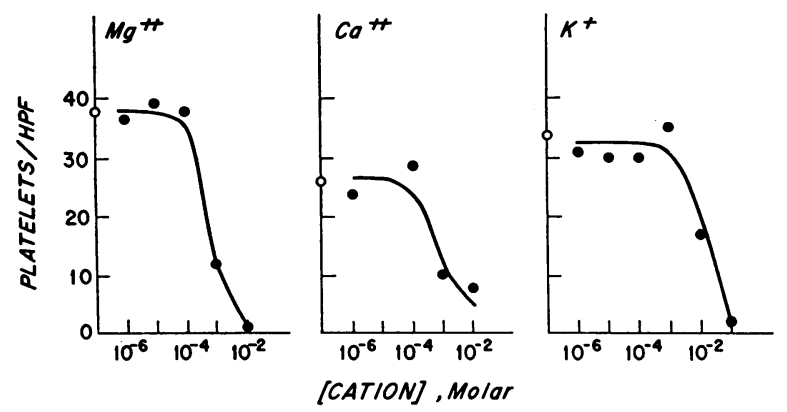

Figure 4 Influence of cation concentration on the random migration of human platelets in duplicate chambers $(\bullet)$ $\mathrm{Mg}^{++}$: the standard $\mathrm{Mg}^{++}$and $\mathrm{Ca}^{++}$-free buffer was constituted with $\mathrm{MgCl}$, at the specified concentrations. Mean migration in $\mathrm{Mg}^{++}$-free buffer $(O)$ was 38 platelets per $\mathrm{HPF}$ at $50 \mu \mathrm{m}$ from the platelet source. $\mathrm{Ca}^{++}$: the standard $\mathrm{Mg}^{++}$and $\mathrm{Ca}^{++}$-free buffer was constituted with $\mathrm{CaCl}_{2}$ at the specified concentrations. Mean migration in $\mathrm{Ca}^{++}$-free buffer (O) was 25 platelets per $\mathrm{HPF}$ at $60 \mu \mathrm{m}$ from the platelet source. $\mathrm{K}^{+}$: the specified amount of $\mathrm{KCl}$ was substituted for $\mathrm{NaCl}$ in $\mathrm{Mg}^{++}$and $\mathrm{Ca}^{++}$-free buffer in which $0.005 \mathrm{M} \mathrm{NaH}_{2} \mathrm{PO}_{4}$ was substituted for $\mathrm{KH}_{2} \mathrm{PO}_{4}$ to make a $\mathrm{K}^{+}$-free buffer. Mean migration in $\mathrm{K}^{+}$-free buffer $(\mathrm{O})$ was 34 platelets per HPF at $50 \mu \mathrm{m}$ from the platelet source. instead of $\mathrm{KH}_{2} \mathrm{PO}_{4} . \mathrm{K}^{+}$concentrations greater than $10^{-3}$ $\mathrm{M}$ were found to inhibit migration in a dose-related manner. The migration observed in standard buffer with a potassium concentration of $5 \times 10^{-8} \mathrm{M}$ was not exceeded by raising or lowering potassium concentration.

As the optimal conditions for platelet movement appeared to reflect an active rather than passive process and as platelets fixed in $10 \%$ formalin before study in standard platelet buffer failed to migrate into the filters, platelet movement was attributed to active migration and studies of its biochemical and pharmacologic modulation were undertaken.

\section{Modulation of platelet migration}

Metabolic inhibitors. Migration in glucose-free buffer was $25 \%$ of that observed in the standard buffer containing glucose $(200 \mathrm{mg} / 100 \mathrm{ml})$, suggesting the requirement of glucose metabolism for migration to occur. 2-Iodoacetamide at concentrations between $10^{-2}$ and $10^{-5} \mathrm{M}$ inhibited migration in a dose-related manner (Fig. 5) with the dose required for $50 \%$ inhibition (IDso) being approximately $10^{-8} \mathrm{M}$. As the 2-iodoacetamide ID 50 may also have been sufficient to influence not only glycolysis but also the hexose monophosphate shunt, the effect of 6-aminonicotinamide on migration was examined. 6-Aminonicotinamide functions as an analog of NADP to inhibit selectively the hexose monophosphate shunt (6). At a concentration of $10^{-5} \mathrm{M}, 6$-aminonicotinamide suppressed migration by 45 and $75 \%$ in two experiments.

Adrenergic and cholinergic agents. At concentrations of $10^{-8} \mathrm{M}$ or greater, epinephrine caused a dose-

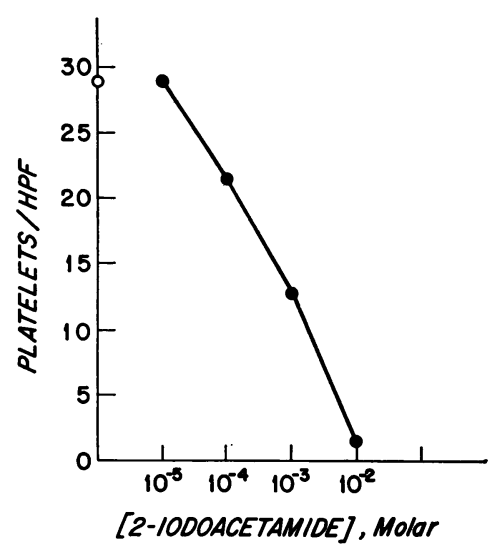

FiguRe 5 Influence of 2-iodoacetamide on the random migration of human platelets $(\bullet)$. Platelets were preincubated at $37^{\circ} \mathrm{C}$ for $15 \mathrm{~min}$ in buffer containing the specified concentrations of 2-iodoacetamide before the platelet suspensions were added to the Boyden chambers. Each point represents the mean number of platelets per HPF at $50 \mu \mathrm{m}$ from the platelet source in duplicate chambers. Control migration in buffer not containing iodoacetamide was 28 platelets per HPF $(O)$. 


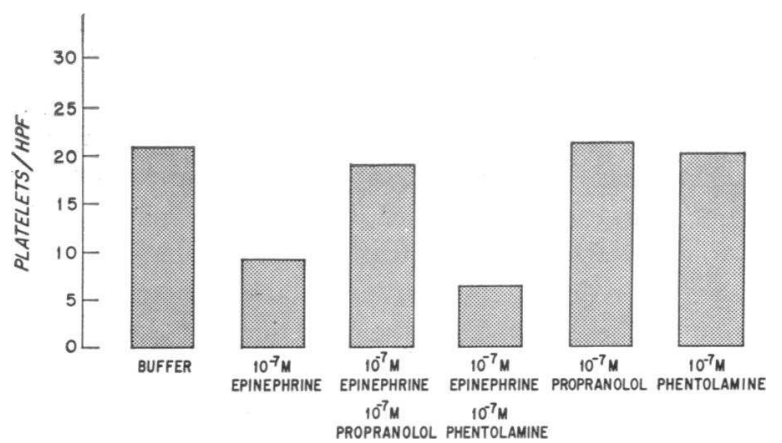

FIGURE 6 Adrenergic receptor specificity of epinephrineinduced inhibition of migration. Platelets were preincubated with propranolol, phentolamine, or buffer for $15 \mathrm{~min}$ at $37^{\circ} \mathrm{C}$ before epinephrine was added. The suspensions were immediately added to the Boyden chambers, and migration was assessed in duplicate filters at $50 \mu \mathrm{m}$ from the platelet source.

related reduction in migration with $59 \pm 12 \%$ (mean \pm SD) inhibition at $10^{-7} \mathrm{M}$ in 10 experiments $(P<0.01)$. Platelets were not visibly aggregated on the upper surface of the filters at concentrations of epinephrine as high as $10^{-5} \mathrm{M}$. To determine whether the action of epinephrine was mediated by the $\alpha$ or $\beta$ receptor, the ability of equimolar amounts of phentolamine, an $\alpha$-blocker, or propranolol, a $\beta$-blocker, to interfere with this effect was studied. The inhibition of migration by $10^{-7} \mathrm{M}$ epinephrine was reversed by equimolar propranolol but not by phentolamine (Fig. 6). Propranolol and phentolamine alone had no effect on migration. Isoproterenol, a pure $\beta$-agonist, was nearly as active on a molar basis (IDso $\cong 10^{-7} \mathrm{M}$ ) as epinephrine in terms of inhibiting migration; while phenylephrine, a pure $\alpha$-agonist, had no effect at concentrations up to $10^{-5} \mathrm{M}$.

Because adrenergic and cholinergic agents often have opposing actions on biologic systems, the effect of the cholinomimetic agent carbachol on migration was determined. Carbachol caused an increase in platelet migration over a broad concentration range $\left(10^{-7} \mathrm{M}-10^{-18}\right.$ $M$ ) with a maximum enhancement of $55 \pm 27 \%$ (mean \pm SD) increase at $10^{-0} \mathrm{M}$ in four experiments $(P<0.05)$.

Prostaglandins and inhibitors of prostaglandin synthesis. Indomethacin, an agent known to inhibit platelet prostaglandin synthetase (7), produced a dose-related inhibition of migration at concentrations greater than $10^{-8} \mathrm{M}$ (Fig. 7) with $53 \pm 17 \%$ (mean \pm SD) inhibition at $10^{-5} \mathrm{M}$ in seven experiments $(P<0.01)$. On the presumption that the effect of indomethacin was mediated by changes in the availability of endogenous prostaglandins, the effect of exogenous prostaglandins $\mathrm{PGE}_{1}, \mathrm{PGE}_{2}$, and $\mathrm{PGF}_{2 \alpha}$ was investigated (Fig. 8). $\mathrm{PGE}_{1}$ caused a dose-related enhancement of migration which was maximal by $2.8 \times 10^{-7} \mathrm{M}$ and fell to a lesser value at concentrations of $1.4 \times 10^{-5}-2.8 \times 10^{-5} \mathrm{M}$. The

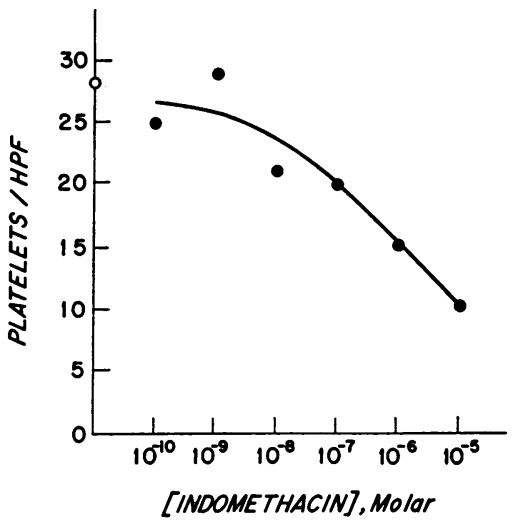

Figure 7 Influence of indomethacin on the random migration of human platelets. Platelets were preincubated at $37^{\circ} \mathrm{C}$ for $15 \mathrm{~min}$ in buffer containing the specified concentrations of indomethacin before the platelet suspensions were added to duplicate Boyden chambers. Each point ( $\bullet$ ) represents the mean number of platelets per HPF at $50 \mu \mathrm{m}$ from the platelet source in duplicate chambers. Control migration in buffer not containing indomethacin was 28 platelets per HPF (O).

enhancement observed at $2.8 \times 10^{-7} \mathrm{M}$ in six experiments was $133 \pm 86 \%$ (mean \pm SD) $(P<0.01)$. The concentration of $\mathrm{PGE}_{2}$ required to achieve enhancement comparable to $\mathrm{PGE}_{1}$ was 10 - to 100 -fold greater. The maximal enhancement by $\mathrm{PGE}_{2}$ occurring at concentrations of $1.4 \times 10^{-5} \mathrm{M}$ to $2.8 \times 10^{-5} \mathrm{M}$ was $121 \pm 76 \%$ (mean \pm $\mathrm{SD})$ in four experiments $(P<0.05) . \mathrm{PGF}_{2 \alpha}$ had no effect over the range in which the enhancing action of $\mathrm{PGE}_{1}$ and $\mathrm{PGE}_{2}$ was recognized.

As exogenous prostaglandins increased platelet migration while an inhibitor of prostaglandin synthetase,

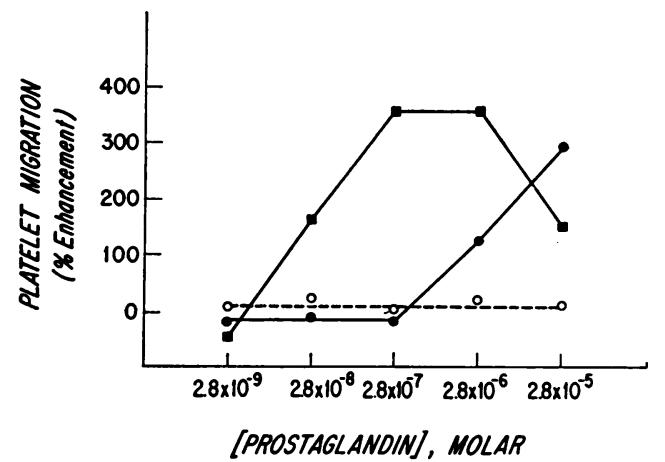

FIGURE 8 Enhancement of the random migration of human platelets by exogenous prostaglandins. Platelets were preincubated for $15 \mathrm{~min}$ at $37^{\circ} \mathrm{C}$ with either $\mathrm{PGE}_{1}$ (E), $\mathrm{PGE}_{2}(\bullet)$, or $\mathrm{PGF}_{2 \alpha}(\mathrm{O})$ at the specified concentrations before being added to the Boyden chambers. Control migration in buffer alone was 10 platelets per HPF at $70 \mu \mathrm{m}$ in the study of $\mathrm{PGE}_{1}$ and $\mathrm{PGE}_{2}$ and 19 platelets per $\mathrm{HPF}$ at $50 \mu \mathrm{m}$ from the platelet source in the study of $\mathrm{PGF}_{2 \alpha}$; triplicate chambers were used. 
indomethacin, suppressed migration, their opposing actions were examined by their simultaneous presence in the Boyden chambers. A PGE 1 concentration of $1.4 \times$ $10^{-6} \mathrm{M}$, a multiple of the lowest concentration causing maximal enhancement, yielded full enhancement despite the presence of $10^{-5} \mathrm{M}$ indomethacin, while the action of lesser concentrations of $\mathrm{PGE}_{1}$ ranged from partial reversal of indomethacin-induced inhibition to restoration of enhancement.

\section{DISCUSSION}

Random migration of human platelets represents a parameter of platelet function which can be assessed in a reproducible manner by modification of the Boyden micropore filter technique for evaluating this function in leukocytes. Random movement of platelets was attributed to active migration because it was maximal at $30-37^{\circ} \mathrm{C}$ (Fig. 1), required metabolic integrity of the platelets (Fig. 5), and was not observed if the platelets had been prefixed in formalin. The suppression of migration by an adrenergic agent (Fig. 6) acting through a $\beta$ receptor and the enhancement achieved with a cholinomimetic agent or certain prostaglandins (Fig. 8) support the view that movement is an active process modulated by specific pharmacologic agents. Platelet movement as assessed by egress from capillary tubes has also been considered an active process based upon recognition of a temperature optimum of $30-37^{\circ} \mathrm{C}$, inhibition by cytochalasin $\mathrm{B}$, and chemotactic responsiveness to stimuli (8-10). Studies of leukocyte migration have also demonstrated that movement from capillary tubes is an active migration but is more dependent on surface adherence and more resistant to metabolic inhibitors than migration in Boyden chambers (11).

Because the platelet is extremely susceptible to aggregation the conditions for collection and handling as well as migration were selected to minimize such a possibility. Calcium ions, which are essential for the aggregation phenomenon, were not added to the migration buffer and were chelated during platelet harvesting by the addition to blood of sufficient sodium citrate anticoagulant to achieve final concentration of $3 \times 10^{-2}$ $\mathrm{M}$ and $\mathrm{pH}$ 6.8. In addition, aggregation occurs most readily at $\mathrm{pH}$ above 7.2 (12) while the migration was most striking at $\mathrm{pH}$ 5.0-6.5 (Fig. 3). That aggregation was in fact difficult to achieve under the experimental conditions for migration was supported by the failure to recognize aggregates on the filters at the highest concentration studied of the aggregating agent epinephrine (Fig. 6). On the other hand, the platelets did have the capacity to aggregate, as evidenced by the presence of aggregates on the upper surface of the stained micropore filter when the calcium-free buffer was constituted with $10^{-2} \mathrm{M}$ calcium or $\mathrm{Mg}^{++}$(Fig. 4); aggregation was possibly due to residual thrombin in the platelet suspension.

Compared to previous studies utilizing purified suspensions of human neutrophilic or eosinophilic polymorphonuclear leukocytes and mononuclear leukocytes, random migration of purified human platelets required a 25-fold greater cell concentration and enumeration halfway through the filter in order to achieve counts comparable to those found on the underside of the filter in leukocyte random migration. The pore size of $8 \mu \mathrm{m}$ required for platelet migration is also utilized in studies of mononuclear leukocytes and basophils $(13,14)$ while the retarding effect of a $3 \mu \mathrm{m}$ pore size is essential to the quantitation of eosinophilic and neutrophilic polymorphonuclear leukocytes. The finding of an optimal protein concentration (Fig. 2) for platelet migration is reminiscent of the protein requirements for migration of various leukocyte populations (15) and is consistent with the interpretation that low protein concentration impeded the process by allowing excessive surface adherence, while a high concentration prevented the degree of adherence required for progressive movement. Random migration of platelets, like that of polymorphonuclear leukocytes (16), is suppressed by 2-iodoacetamide and 6-aminonicotinamide (Fig. 5), agents which suppress glycolysis and the hexose monophosphate shunt, respectively. One apparent difference between the inherent requirements for spontaneous migration of human platelets as compared to rabbit neutrophilic leukocytes is that platelet migration is optimal in the absence of added magnesium and calcium (Fig. 4), while leukocyte migration is reduced by low divalent cation concentration (17). The inhibition of platelet migration by divalent cations can be attributed, however, to the aggregation of platelets by thrombin contaminating the suspension of platelets. It should be noted in considering any of the differences in the migration characteristics for platelets as compared to other cell types that the standard buffer is phosphate-buffered saline, $\mathrm{pH} 6.8$, containing only added glucose and gelatin, whereas leukocyte migration is assessed in enriched buffers, e.g., Medium 199 (13, 14). The basis for selecting a simple buffer was to minimize platelet aggregation and to facilitate determination of medium requirements.

The capacity of epinephrine and the prostaglandins to initiate and/or modulate platelet function has been noted in the platelet aggregation and release reactions $(18,19)$ while an effect of a cholinomimetic agent has not received comparable attention. Although the effect of epinephrine on the aggregation-release reaction is to initiate or facilitate through its $\alpha$ potential (18), its action on random migration is inhibitory and dependent on interaction with a $\beta$ receptor. This conclusion is 
based on the capacity of equimolar propranolol but not phentolamine to prevent epinephrine inhibition of random migration (Fig. 6) and on the finding that isoproterenol is nearly as active on a molar basis as epinephrine while phenylephrine is without effect. This recognition of a platelet function modulated by a $\beta$ receptor is consistent with the report of $\beta$-receptor-mediated platelet disaggregation (20). Whether $\beta$-receptor-modulated platelet functions will prove a characteristic of other in vitro functions under comparable buffer conditions is not established. In this regard, Ahlquist observed that the relative predominance of $\alpha$ vs. $\beta$ potential in a model system is influenced by the buffer characteristics (21).

The opposing effect of adrenergic and cholinergic stimuli on biologic systems has more recently been appreciated in in vitro studies of effector cells of the inflammatory response such as tissue mast cells (22), thymus-derived lymphocytes (23), and polymorphonuclear leukocytes $(24,25)$. $\beta$-Adrenergic stimuli suppressed the antigen-induced release of chemical mediators from lung fragments sensitized with $\operatorname{IgE}$, the thymus lymphocyte-mediated destruction of allo-incompatible target cells, and the release of lysosomal enzymes by neutrophilic leukocytes during phagocytosis, while cholinergic stimuli enhanced each of these phenomena. The concentration of cholinomimetic agents active in each of these systems was several orders of magnitude less than those of the adrenergic stimuli. Hence, the demonstration of cholinergic enhancement of spontaneous platelet migration with a peak effect in the nanomolar range or less is entirely consistent with the findings involving other cells engaged in different functions. By analogy to the other systems (26), the opposing action of $\beta$-adrenergic and cholinergic stimuli on platelet migration could relate to their influence on the intracellular levels of the cyclic nucleotides, cyclic AMP, and cyclic GMP, respectively.

The findings that $\mathrm{PGE}_{1}$ as well as high concentrations of $\mathrm{PGE}_{2}$ enhanced platelet migration (Fig. 8) are in contradistinction to their inhibitory action on the platelet aggregation-release reaction in a comparable dose (19). The additional finding that indomethacin, an inhibitor of platelet prostaglandin synthetase (7), suppressed random migration (Fig. 7) suggests that a certain level of endogenous prostaglandin formation is essential to the migration process. This is supported by the capacity of indomethacin to prevent $\mathrm{PGE}_{1}$-mediated enhancement at the usual optimal dose, although a several fold increase in this dose will overcome the indomethacin effect. The influence of indomethacin on the expression of the prostaglandin enhancing action may mean that intermediates in prostaglandin biosynthesis act in concert with the end product. The capacity of indomethacin to diminish the effect of exogenous prosta- glandins has also been observed in an in vitro system concerned with prostaglandin inhibition of antigeninduced mitogenesis (27). Irrespective of whether intermediates in prostaglandin biosynthesis or the end products themselves are essential to migration and its augmentation by exogenous prostaglandins is the additional consideration of whether these effects involve a change in the ratio of cyclic nucleotides. A precise interpretation of the indomethacin or PGE 1 effects on platelet function will require determination of the prostaglandins formed and the changes in the level of cyclic nucleotides in relation to pharmacologic and surface stimuli.

\section{ACKNOWLEDGMENTS}

This work was supported by grants AI-07722, AI-10356, and RR-05669 from the National Institutes of Health.

\section{REFERENCES}

1. Hellem, A. J. 1968. Platelet adhesiveness. Ser. Haematol. 1: 99-145.

2. Hampton, J. R. 1967. The study of platelet behavior and its relevance to thrombosis. J. Atheroscler. Res. 7: 729-746.

3. Boyden, S. 1962. The chemotactic effect of mixtures of antibody and antigen on polymorphonuclear leukocytes. J. Exp. Med. 115: 453-466.

4. Lachmann, P. J., A. B. Kay, and R. A. Thompson. 1970. The chemotactic activity for neutrophil and eosinophil leukocytes of the trimolecular complex of the fifth, sixth, and seventh components of human complement $(\mathrm{C} \overline{567})$ prepared in free solution by the "reactive lysis" procedure. Immunology. 19: 895-899.

5. Luna, L. G. 1968. Manual of Histologic Staining Methods of the Armed Forces Institute of Pathology. McGraw-Hill Book Company, New York. 3rd edition. 3.

6. Ammon, H. P. T., and J. Steinke. 1972. Effect of 6-aminonicotinamide on insulin release and C-14 glucose oxidation by isolated pancreatic rat islets: difference between glucose, tolbutamide and aminophylline. Endocrinology. 91: 33-48.

7. Smith, J. B., and A. L. Willis. 1971. Aspirin selectively inhibits prostaglandin production in human platelets. Nat. New Biol. 231: 235.

8. Nathan, P. 1973. The migration of human platelets in vitro. Thromb. Diath. Hacmorrh. 30: 173-177.

9. Lowenhaupt, R. W., M. A. Miller, and H. I. Glueck. 1973. Platelet migration and chemotaxis demonstrated in vitro. Thromb. Res. 3: 477-486.

10. Lowenhaupt, R. W., and H. I. Glueck. 1974. The effect of cytochalasin B on platelet migration. Fed. Proc. 33 : 243. (Abstr.)

11. Miller, M. E. 1974. Chemotaxis and random mobility. Their clinical and biologic differentiation. In Chemotaxis: Biology and Biochemistry. E. Sorkin, editor. S. Karger, Basel. In press.

12. Aster, R. H., and J. H. Jand1. 1964. Platelet sequestration in man. I. Methods. J. Clin. Invest. 43: 843-855.

13. Goetzl, E. J., I. Gigli, S. I. Wasserman, and K. F. Austen. 1973. A neutrophil immobilizing factor derived from human leukocytes. II. Specificity of action on polymorphonuclear leukocyte mobility. J. Immunol. 111: 938-945. 
14. Kay, A. B., and K. F. Austen. 1972. Chemotaxis of human basophil leukocytes. Clin. Exp. Immunol. 11: 557-563.

15. Zigmond, S. 1972. Studies on polymorphonuclear leukocyte locomotion and chemotaxis. Ph.D. Thesis at the Rockefeller University, Division of Cellular Immunology. New York.

16. Goetz1, E. J., and K. F. Austen. 1974. Stimulation of human neutrophil leukocyte aerobic glucose metabolism by purified chemotactic factors. J. Clin. Invest. 53: 591599.

17. Becker, E. L., and H. L. Showell. 1972. The effect of $\mathrm{Ca}^{2+}$ and $\mathrm{Mg}^{2+}$ on the chemotactic responsiveness and spontaneous motility of rabbit polymorphonuclear leukocytes. Z. Immun. Forsch. Bd. 143: S466-476.

18. Mills, D. C. B., and G. C. K. Roberts. 1967. Effects of adrenaline on human blood platelets. J. Physiol. (Lond.). 193: 443-453.

19. Kloeze, J. 1969. Relationship between chemical structure and platelet-aggregation activity of prostaglandins. Biochim. Biophys. Acta. 187: 285-292.

20. Abdulla, Y. H. 1969. $\beta$-Adrenergic receptors in human platelets. J. Atheroscler. Res. 9: 171-177.

21. Ahlquist, R. P. 1966. The adrenergic receptor. J. Pharm. Sci. 55 : 359-367.
22. Kaliner, M., R. P. Orange, and K. F. Austen. 1972. Immunological release of histamine and slow reacting substance of anaphylaxis from human lung. IV. Enhancement by cholinergic and alpha adrenergic stimulation. J. Exp. Med. 136: 556-567.

23. Strom, T. B., C. B. Carpenter, M. R. Garovoy, K. F. Austen, J. P. Merrill, and M. Kaliner. 1973. The modulating influence of cyclic nucleotides upon lymphocytemediated cytotoxicity. J. Exp. Med. 1.38: 381-393.

24. Ignarro, L. J., and C. Colombo. 1973. Enzyme release from polymorphonuclear leukocyte lysosomes: regulation by autonomic drugs and cyclic nucleotides. Science (Wash. D. C.), 180: 1181-1185.

25. Ignarro, L. J. 1974. Stimulation of phagocytic release of neutral protease from human neutrophils by cholinergic amines and cyclic 3',5'-guanosine monophosphate. J. Immunol. 112: 210-214.

26. Ignarro, L. J., and W. J. George. 1974. Mediation of immunologic discharge of lysosomal enzymes from human neutrophils by guanosine $3^{\prime}, 5^{\prime}$-monophosphate. $J$. Exp. Med. 140: 225-238.

27. Shenton, B. K., E. J. Field, A. F. Rogers, J. A. Carney, J. A. C. Sykes, and J. Mertin. 1973. Prostaglandins and cellular immunity: a regulatory mechanism. Int. Res. Commun. Sys. Dec. 8-10-1: 21. 